\title{
Fractura deprimida cerrada de la fosa posterior en un anciano
}

\section{Closed depressed fracture of the posterior fossa in an elderly patient}

\author{
L.R. Moscote, J.J. Gutiérrez, S.M. Castellar, G. Alcalá
}

\section{Sr. Director:}

El trauma craneoencefálico es una causa de mortalidad en los países desarrollados y también en subdesarrollados ${ }^{1,2}$. Una fractura craneal es considerada deprimida cuando cualquier porción de la tabla externa de la fractura está por debajo de la tabla interna del hueso inmediatamente paralelo al defecto craneal. Las fracturas craneales pueden presentarse en cualquier región de la bóveda craneal, siendo las fracturas deprimidas cerradas de la fosa posterior muy raras y asociándose traumas de alta energía de los que existen pocos casos publicados en la literatura médica.

Varón de 72 años que presentaba lesiones en la cabeza. Al ingreso presentaba Glasgow de 12/15. Se observaba una pequeña herida lacerada en la región occipital derecha, sin evidencia de fístula de líquido cefalorraquídeo a través de la herida. La tomografía axial computada mostró una fractura deprimida derecha occipital, acompañada de una zona contusional en el cerebelo (Fig. 1). No se consideró tratamiento quirúrgico. El paciente fue trasladado a la unidad de cuidados intensivos. La fistula de líquido cefalorraquídeo evidenciada por el oído derecho, se resolvió a los 7 días. El paciente desarrolló meningitis a los 10 días y se inició tratamiento con antibióticos (ceftriazona $2 \mathrm{~g}$. iv c/12 horas). El paciente falleció a los 25 días por complicaciones cardiacas. Este tipo de lesiones, infrecuente en la actualidad, no tienen un tratamiento neuroquirúrgico definido.

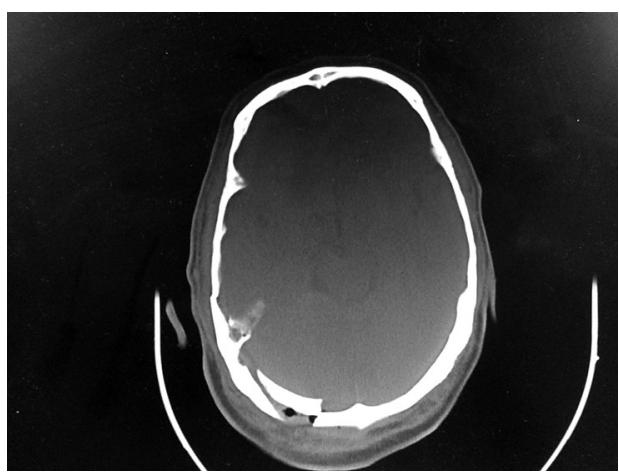

Figura 1. Fractura deprimida occipital derecha.

Las fracturas de cráneo son las lesiones primarias del cráneo. Las fracturas de fosa posterior son raras. Se considera que las múltiples capas de músculo hacen que sea menos susceptible a la fractura ${ }^{3}$. Las fracturas de cráneo son comunes después de los accidentes de tráfico, traumatismos, lesiones, entre otros. Posteriormente a un
Universidad de Cartagena. Cartagena. Colombia

Recepción: 20 de julio de 2012

Aceptación provisional: 21 de septiembre de 2012

Aceptación definitiva: 19 de diciembre de 2012

\section{Correspondencia:}

Luis Rafael Moscote-Salazar

Universidad de Cartagena

E-mail: neuromoscote@aol.com 
trauma craneoencefálico los principales hallazgos que se pueden identificar son: las fracturas craneales (lineal o conminuta, deprimida o no deprimida, abierta cerrada, fracturas de base de cráneo de senos y orbita); colecciones hemáticas (hematoma epidural, hematoma subdural, hemorragia intracerebral, intraventricular o subaranoidea); edema cerebral; hidrocefalia; isquemia/anoxia, neumoencéfalo; desviación de la línea media. La presencia de una fractura de cráneo implica un trauma de considerable energía, sin embargo, algunos pacientes no presentan focalización neurológica. Una fractura lineal es indicación de la severidad del traumatismo, por lo que se debe estar alerta de la presencia de algún daño intracraneal. En relación a las fracturas deprimidas, si la tabla externa de uno de los fragmentos óseos es llevada hacia adentro quedando por debajo de la tabla interna del cráneo intacto, ha tenido lugar cuando un objeto con gran energía cinética hace contacto con una pequeña área del cráneo. Entre 5-7\% coexisten con hematomas intracraneales y un $12 \%$ implican al seno dural subyacente. El manejo neuroquirúrgico es controvertido. La búsqueda bibliográfica realizada reveló sólo dos casos publicados de fractura cerrada de depresión de la fosa posterior $^{4,5,6}$.

\section{BIBLIOGRAFÍA}

1. Besenski N. Traumatic injuries: imaging of head injuries. Eur Radiol 2002; 12: 1237-1252.

2. Provenzale JM. Imaging of traumatic brain injury: a review of the recent medical literature. AJR 2010; 194: 16-19.

3. Motozaki T, Yамамото T. Unusual case of depressed fracture in the posterior cranial fossa associated with the syndrome of acute central cervical spinal cord INJURY. NEUROSURG REv 1989;12 (Supl 1): 595-599.

4. Colak A, Berker M, Ozcan OE. Occipital depression fractures in childhood. A report of 14 cases. Childs Nerv Syst 1991; 7: 103-105.

5. Bharath R, Arivazhagan A, Pruthi N, Bhat Di. Rare case of closed depressed fracture of the posterior fossa in an adult causing brainstem dysfunction: Management dilemmas. Neurol India 2011; 59: 778-779.

6. Neubauer UJ. Extradural haematoma of the posterior fossa. Twelve years experiences with CT-scan. Acta Neurochir (Wien) 1987; 87: 105-111. 